\title{
Additive manufacturing: state of the art and potential for insect science
}

\author{
Mourad Jaffar-Bandjee*1,2 Jérôme Casas $^{1}$, and Gijs Krijnen ${ }^{2}$ \\ ${ }^{1}$ Institut de Recherche sur la Biologie de l'Insecte, UMR 7261, CNRS, Université de Tours, \\ France \\ ${ }^{2}$ Robotics and Mechatronics, Technical Medical Centre, University of Twente, the \\ Netherlands
}

13 June 2018

${ }^{*}$ Corresponding author : mourad. jaffar-bandjee@etu. univ-tours.fr 


\section{Abstract}

Additive Manufacturing has become an efficient tool to study insect-inspired biomimetic solutions. Indeed, it can build objects with intricate 3D-shapes and use materials with specific properties, such as soft materials. From biomaterials to biostructures or biosensors, Additive Manufacturing allows more possibilities in terms of design and functions. Reciprocally, insect-inspired technological solutions can be implemented to enhance Additive Manufacturing processes providing for example biocompatible structures that can successfully host living cells. We believe that, thanks to its continuous progress, Additive Manufacturing will play a growing role in the development of insect-inspired solutions.

\section{Introduction}

Biological systems are a wonderful source of inspiration to find solutions for a large variety of problems. Nature had millions of years to develop efficient and original ways to deal with challenges, e.g. varying from all kinds of locomotion to group organization, from abiotic constraints to predator evasion. Even if not all these solutions might be relevant for human applications, they may reveal interesting phenomena or mechanisms.

Insects, and in a broader sense arthropods, have a large range of ecological conditions: they can crawl on the ground, swim, fly, live in caves in complete darkness [1] or even survive space conditions ([2], Panarthropoda clade). Moreover, being part of the same phylogenetic group, they had to evolve various solutions based on the same basic tools and materials, e.g. all the cuticles and hard parts of insects contain chitin [3] with various mechanical properties. Insects are thus a rich and promising group for biomimetics [4].

However, insects are of relatively small size so it is sometimes difficult to study them. As the 3D-shape of an organ or any other part of interest is also closely linked with its function, manufacturing small-size objects with specific $3 \mathrm{D}$-shapes would be a great help to investigate insect-related mechanisms. Well-known photolithography based fabrication technologies such as MEMS, CNC milling or moulding are wonderful technologies to produce a variety of objects but they have their limitations, e.g. size-wise or in producing various kinds of 3D shapes (Table 1). On the other side, Additive Manufacturing (AM), with 3D printing its most well-known representative, produces highly customizable objects with far more freedom regarding their 3D-shapes than traditional manufacturing technologies.

\begin{tabular}{ccccc}
\hline Technology & Photolithography & Additive Manufacturing & CNC & Moulding \\
\hline Dimensionality & 2,5 -D (stratified) & 3D & 3D, limited & 3D, limited \\
Fabrication & Batchwise & Piecewise & Piecewise & Batchwise \\
Materials & Inorganic & Organic & Inorganic & Organic \\
& Mostly stiff & Stiff and flexible & Stiff & Stiff and flexible \\
& Linear & Creep, hysteresis & Linear & Creep, hysteresis \\
Resolution & $\mathrm{nm}-\mu \mathrm{m}$ & $\mu \mathrm{m}-\mathrm{mm}$ & $0.1 \mu \mathrm{m}-\mathrm{mm}$ & $\mu \mathrm{m}-\mathrm{mm}$ \\
Initial costs & High & Low & Low & High \\
\$/piece & Low & Medium & High & Low \\
Customisation & None & Per piece & Per piece & None \\
Lead time & Long & Short & Short & Long \\
\hline
\end{tabular}

Table 1: Comparison of the characteristics of various traditonnal manufacturing processes with Additive Manufacturing, adapted from [5], CNC = Computer Numerical Control

\section{Additive manufacturing}

AM literally entails the class of fabrication technologies that are based on adding materials, rather than removing (e.g. etching, milling, spark erosion, etc.) from a piece. It is best known for 3D printing, e.g. a layer-by-layer manufacturing process. Because of this particular process (fig1), 3D printing can produce all possible 3D-shaped objects as long as it does not collapse during building, e.g. by gravitational forces [6] . 


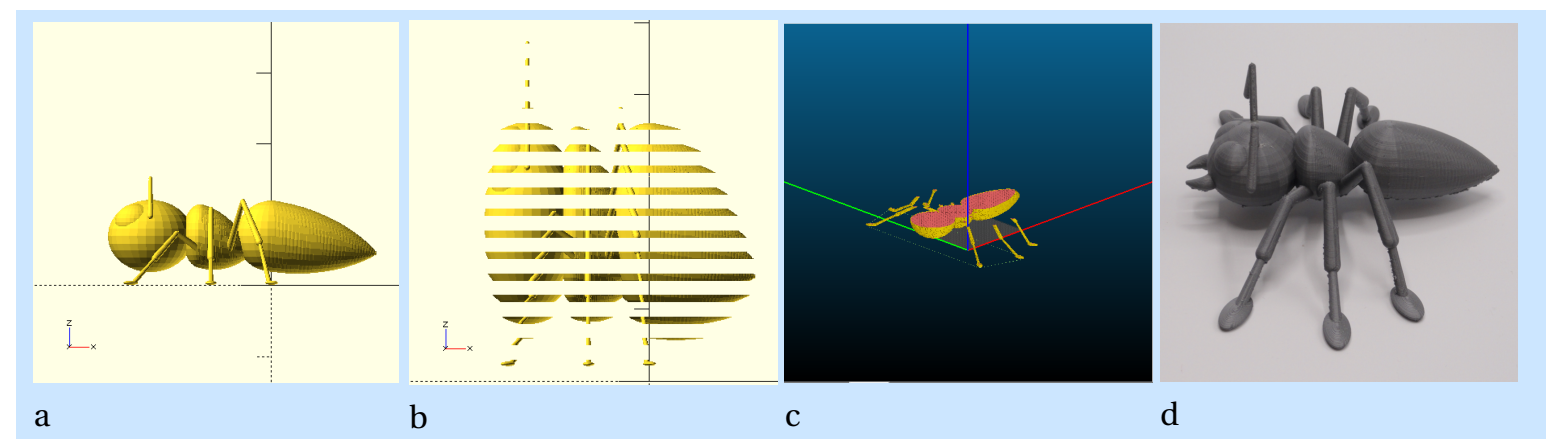

Fig. 1: Principle of Additive Manufacturing processes. a: 3D model of ant (Openscad v2015.03-2), $b$ : Slicing of the 3D model (Openscad v2015.03-2), c: Layer-by-layer building process (Slic3r v1.2.9), d: Printed model

AM is divided in 7 kinds of processes depending on how each additional layer of material is created [7] (Table 2). The choice of process is a critical one as it defines which kind of materials can be used in the process, the resolution that can be obtained and if there are any limits on the range of possible 3D-shapes. For example, Stereolithography (SLA) is a process where the new layer of material is cured by UV light within a layer of liquid photopolymers. Materials are thus restricted to photopolymers or materials that can be functionalised using photopolymers. Also, overhanging structures may need support to be produced [8].

Besides classical SLA processes, it is worth noticing the existence of 2-photon polymerization technique (Nanoscribe, Eggenstein-Leopoldshafe, Germany) which allows very good accuracy $(0.5 \mu \mathrm{m})$ for complexshaped objects. Alternatively, FDM (Fused Deposition Modelling) is a highly customizable process: here molten material is extruded through a nozzle. By combining several nozzles, it is possible to use several materials with various properties or colors [9] or even to create one's own material [10]. Another process often used in biomimetics research is Polyjetting. Here, droplets of material are jetted by a printer head to create each new layer. By adding more print nozzles, it is possible to use multiple materials in the same print or even create materials by mixing various components [11].

Progress has also been made with respect to materials with special properties. Conductive materials are now available [12] as well as soft materials [13] or even piezoelectric materials [14]. These kinds of materials are critical to produce actuators and sensors.

Despite the resolution of AM getting close to the micrometric scale (table 2), it should be mentioned that high resolution alone is often insufficient to mimic insects, as a general aspect of biology is that its structures cover 7-9 orders of magnitude in size, from nanometers up to (centi)meters, largely surpassing even the most advanced 3D printers currently available. 


\begin{tabular}{|c|c|c|c|c|}
\hline Category & Description & Advantages and disadvantages & $\begin{array}{l}\text { Material } \\
\text { resolu- } \\
\text { tion }\end{array}$ & $\begin{array}{l}\text { Capability } \\
\text { of multiple } \\
\text { materials } \\
\text { printing }\end{array}$ \\
\hline Stereolithography & $\begin{array}{l}\text { Stereolithography Apparatus (SLA) } \\
\text { and DLP (Digital Light Processing) } \\
\text { cure a layer of photopolymers with } \\
\text { laser light point-by-point or a } \\
\text { surface all at once }\end{array}$ & $\begin{array}{l}\text { + High dimensional accuracy and trans- } \\
\text { parent material available } \\
\text { - Restricted to photopolymers, time } \\
\text { consuming material changing, mate- } \\
\text { rial contamination and need of support } \\
\text { structure }\end{array}$ & Good & Poor \\
\hline Material extrusion & $\begin{array}{l}\text { Fused or room temperature } \\
\text { materials are extruded through a } \\
\text { nozzle. Ex: Fused Deposition } \\
\text { Modeling (FDM) and } \\
\text { 3D-bioprinting }\end{array}$ & $\begin{array}{l}\text { + Easy and cheap mechanisms, good } \\
\text { materials properties, living cells can be } \\
\text { incorporated } \\
\text { - Relatively low dimensional accuracy } \\
\text { and mechanical strength }\end{array}$ & Medium & Good \\
\hline Powder bed fusion & $\begin{array}{l}\text { Powder particles are fused together } \\
\text { using a power source such as laser, } \\
\text { heat or electron beam. Ex: } \\
\text { Selective Laser Sintering (SLS) or } \\
\text { Electron Beam Melting (EBM) }\end{array}$ & $\begin{array}{l}\text { + Wide range of materials, great mate- } \\
\text { rial properties, high material strength, } \\
\text { no need of support structure } \\
\text { - Thermal stress, degradation, accuracy } \\
\text { limited by the particle size of materials, } \\
\text { material contamination when changing } \\
\text { to other materials, require atmosphere } \\
\text { control for metals }\end{array}$ & Low & Fair \\
\hline $\begin{array}{l}\text { Directed energy } \\
\text { deposition }\end{array}$ & $\begin{array}{l}\text { Materials, in the shape of powders } \\
\text { or wires, are melted using a laser or } \\
\text { electron beam and deposited } \\
\text { according to a desired shape. Ex: } \\
\text { direct metal deposition }\end{array}$ & $\begin{array}{l}\text { + Wide range of materials, great mate- } \\
\text { rial properties } \\
\text { - Low dimensional accuracy, thermal } \\
\text { stress, requires atmosphere control, re- } \\
\text { quires machining process to finish the } \\
\text { part }\end{array}$ & High & Fair \\
\hline Sheet lamination & $\begin{array}{l}\text { Sheets of materials are cut and } \\
\text { bound together. Ex: Ultrasonic } \\
\text { Additive Manufacturing (UAM) } \\
\text { uses ultrasounds to merge layers of } \\
\text { metal }\end{array}$ & $\begin{array}{l}\text { + Fast process, high dimensional accu- } \\
\text { racy } \\
\text { - Great amount of scrap, delamina- } \\
\text { tion, requires changeover when chang- } \\
\text { ing materials }\end{array}$ & Low & Fair \\
\hline Material jetting & $\begin{array}{l}\text { Material drops are jetted from } \\
\text { printheads in a similar way as } \\
\text { 2D-printing. }\end{array}$ & $\begin{array}{l}\text { + Fast process, wide range of materials, } \\
\text { materials mixing on droplet scale, good } \\
\text { accuracy } \\
\text { - Limited to jettable materials, clogging } \\
\text { problem }\end{array}$ & High & Excellent \\
\hline Binder jetting & $\begin{array}{l}\text { A binder is jetted on a bed of } \\
\text { powder to stick particles together. } \\
\text { This process was originally known } \\
\text { under the name 3D-Printing }\end{array}$ & $\begin{array}{l}\text { + Low temperature and fast process } \\
\text { - High porosity, low surface quality, ac- } \\
\text { curacy limited by particle size, difficult } \\
\text { to remove trapped materials }\end{array}$ & Medium & Good \\
\hline
\end{tabular}

Table 2: Characteristics of the different AM processes, adapted from [15] for the process description column [16] and its references for the advantages and disadvantages and the material resolution and [17] for the multi-material capabilities. The Nanoscribe (Eggenstein- Leopoldshafen, Germany) was put apart in the Stereolithography category because of its special technology which allows to reach sub- micrometer accuracy.

\section{Biomaterials and structure}

Insects are small and lightweight and they can synthesize materials with a large range of differing properties depending on the needed functionality of the material. Some of them are termed composite materials and obtain their mechanical properties from both the properties and the spatial arrangement of their constituents. From a broader point of view, structures built by arthropods, such as spider webs, can give new ideas to architecture [18].

\section{Structural materials}

Biomaterials possess properties that make them special in regards to their human-made counterparts. They are lightweight, synthesizable in water solutions and biodegradable [19]. Many biomaterials are also composite materials: they are composed of several materials that are deposited in such a way that the resulting composite material can have better mechanical properties then any of its constituents [20]. This is for ex- 
ample the case of insect cuticle which is a mix of chitin nanofibers, water and various proteins and whose Young modulus varies from $1 \mathrm{kPa}$ to $20 \mathrm{GPa}$ [3].

AM and biomaterials can benefit from each other. Firstly, AM can play an important role in the development and use of composite and structural materials. Indeed, the possibility to produce and study such materials [20] has already been demonstrated. Water-repellent surface structures of springtails were also successfully reproduced and enhanced with AM to become repellent for almost any liquid [21]. Secondly, $\mathrm{AM}$ and more specifically FDM can produce materials with anisotropic properties by, for example, printing materials that are composed of a matrix and parallel fibers [22] as it is the case in silk [23]. The other way around, biomaterials can give new opportunities to AM, especially in 3D bio-Printing [24]. However, in traditional FDM, a filament of plastic is molten and made to flow through a nozzle. As 3D bio-printing concerns cells, a substance which can flow at room temperature and which is biocompatible and biodegradable is necessary. Bio-inks based on spider silk fibers have been created to meet these criteria [25].

On a larger scale, the two-way interaction still holds. AM can learn from insects how to design and produce 3D-shapes. This is especially the case for FDM which process is similar to the extrusion of silk by insects. An FDM nozzle put on a robot arm (Kukka arm) was shown to be able to mimick the cocoon construction process of a silkworm [26] (fig2e).

\section{Architecture}

AM can help studying biostructures that have optimized load distribution such as honeycombs [27] and spiderwebs [28] (fig2c). Those bio-structures have concrete applications, in architecture for example. Frei Otto who popularized lightweight structures was inspired by spiderwebs among others [18]. On the micro-scale, geometries of the stings of mosquitoes [29] and bees [30] were reproduced to create high-quality needles (fig2b).

\section{Bioinspired locomotion}

Insects live in very diverse ecological environments. Thus, they developed various strategies to move depending on whether they walk on solid or liquid surfaces, fly in the air or swim in water. Consequently, insects are a great source of inspiration for small-sized robots as they developed lightweight and efficient solutions to locomotion. The 3D-shape of organs such as wings or legs play a significant role in the performance of locomotion. AM can produce such complex 3D-objects and, thus, help to better understand the mechanisms of locomotion. These solutions can then be implemented to design better robots.

Actuators

Before being able to produce a full robot, AM must develop the capability to produce actuation. To this end, fabrication of the required actuators is a challenge, as they are composed of mobile parts, need ample energy supply and effective and efficient transduction mechanisms. Thanks to the development of soft materials for AM, it is now possible to produce soft actuators [31]. Actuators inspired from biological fiber muscles have even been developed [32]. However, this is a new development and another solution is to embed traditional actuators within 3D-printed parts [33].

\section{Bioinspired robots}

Locomotion is an important field for robotics [34]. Better understanding the physics of the various modes of locomotion of insects, such as walking and crawling, is crucial in designing better robots. In this regard, beetle [35] and leafhopper [36] legs have been investigated with the help of AM in order to understand how their shapes were linked to their functions (fig2g). A similar approach was conducted to better understand the physics of insect crawling [37, 38]. However, only the bodies of the crawling robots were built with AM technologies. Traditional actuators were then assembled with the robot. Cutkosky and his team [39] used another manufacturing process called Shape Deposition Manufacturing (SDM), a process which combines moulding, parts embedding and assembly, to produce their walking robot inspired from cockroach because it is a straightforward method to embed actuators. The recent development of Hybrid Deposition Manufacturing, a technology comparable to SDM but with more parts being produced by 3D printing [40], could give 


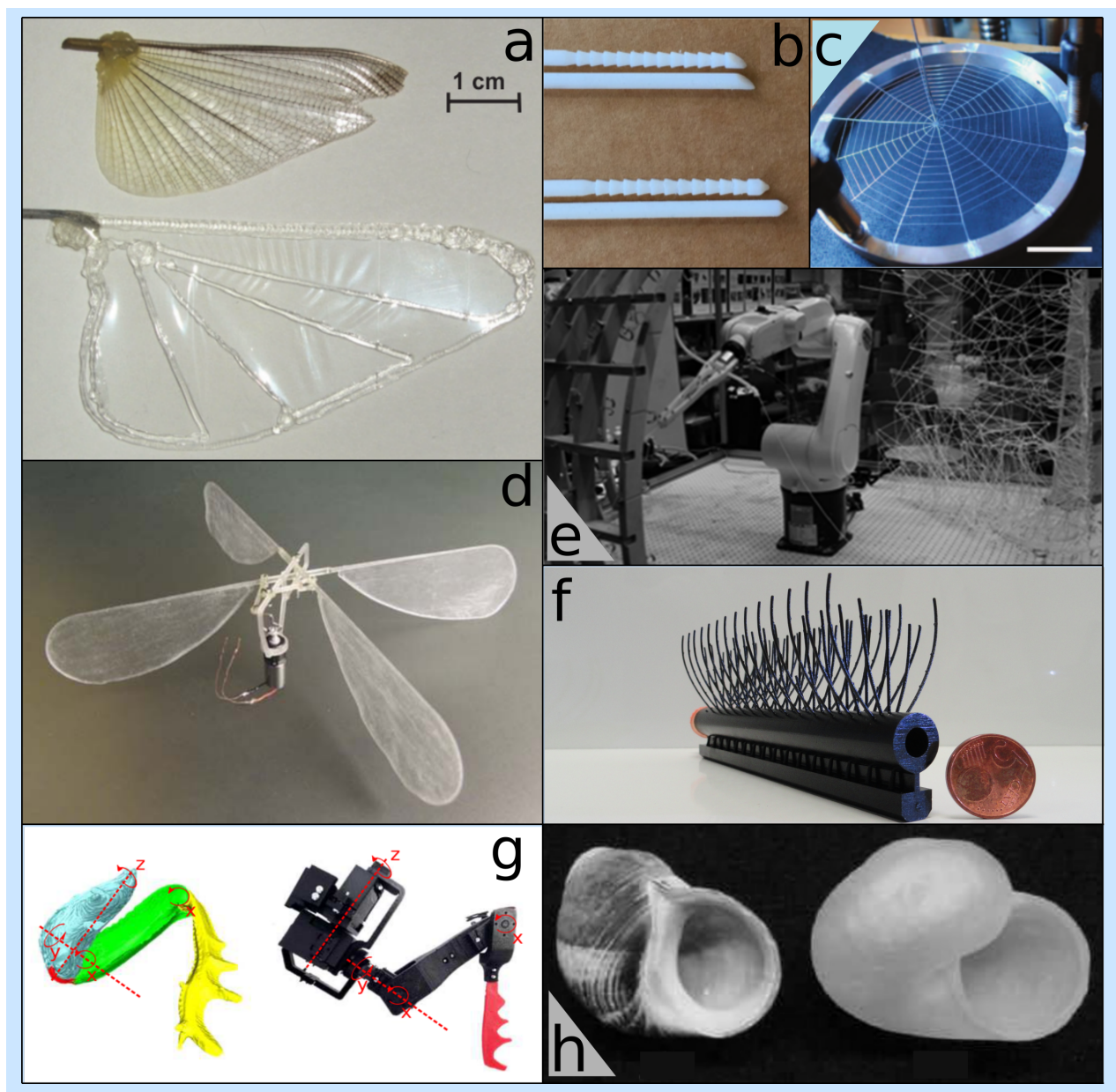

Fig. 2: Application of Additive Manufacturing to insect-inspired biomimetics. a: Dragonfly-inspired wing [41]; b: Honeybee-inspired needles [30]; c: Biomimetic spiderweb [28]; $d$ : Micro air vehicle with insect-inspired wings [42]; e: Robot arm building a cocoon-like structure in a similar way as silkworm [26]; f: Artificial antenna structure inspired from moth [43]; g: Multifunction beetle-inspired leg [35]; $h$ : Natural and artificial shells for hermit crab preference tests [44]

Additive Manufacturing an important role in this domain.

\section{Flying robots}

Biomimetic flying robots have been under study for almost 30 years [45] and insects have gained a special focus as an effective source of inspiration [46]. Indeed, insects are small and some of them have excellent flying capabilities. They perform flapping-wing flight which requires flexible wings [47]. Most of the work about insect-inspired flying robots has thus been dealing with wing shape and flexibility. Although CNC milling [48] was also used, Additive Manufacturing is a more convenient tool to investigate how wing geometry is related to flight performance. Most of the time, only the frame of the wing was produced with AM and subsequently a film was applied to mimick the membrane [49, 41] (fig2a). Richter et al [42] (fig2d) were the only ones to completely produce wings with AM technology. Wing flapping physics has received ample attention and AM can help produce customized mechanical parts [42, 50].

Insect-inspired biomimetic AM can have surprising applications, for example in a culinary context: inspired by the rove beetle, a cocktail boat was put into motion on a water surface using the Marangoni propulsion [51]. 


\section{Bioinspired sensors}

Insects have evolved multiple sensors to interact with their environment. Here again, the 3D-shape of the sensors can have a profound importance and, thus, AM could be an efficient tool to investigate or reproduce biosensors [52].

Moth antennas are very sensitive olfactory sensors and they have a complex 3D-shape. Thanks to AM, it was possible to partly reproduce this shape and investigate its efficiency [53]. Arthropod eyes are also a good source of inspiration for biosensors. Studies and production of biomimetic eyes have been undertaken [54], showing the high interest in this kind of sensors. However, only during the last years was AM able to print micro-optics $[55,56]$ and a project to produce a biomimetic eye entirely through AM is currently in progress [57]. A last kind of biomimetic sensor developed with AM is an acoustic device inspired from a locust [58] thanks to the new possibility to use piezoelectric materials.

The literature about AM and insect-inspired sensors is actually quite recent. However, with the continuing technological developments of AM, accuracy is increased and a broader range of materials is available. We believe that this progress will help to accelerate design and study biosensors with AM in the near future.

\section{Discussion}

Additive Manufacturing is a group of evolving technologies. Processes are improved, accuracy is increasing, printers become cheaper and an increasing variety of materials is now usable such as flexible and/or conductive materials. This progress gives AM an increasing potential to produce objects with specific properties. For example some biomaterials display gradient properties which may be reproduced by e.g. polyjetting. However, AM is not always used for its enabling capabilities: it may as well just be a method to conveniently and cheaply produce simple objects that help studying certain phenomena [59].

A dichotomy can be observed between the investigations aiming at mimicking the shape of an insect, or one of its organs, for technological applications, and those where the mechanisms are investigated in a biological context. In the former case, the challenge is usually a technical one: for example, Richter et al succeeded in manufacturing a flying robot [42]. In the latter case, AM is a very useful tool as it allows to produce similar objects with different parameters to better understand how they affect the performance of the real animal [41].

AM can also be used to investigate insect-environment interactions: artificial shells (fig2h) and flowers with various geometrical parameters were offered to respectively hermit crab [44] and tobacco hawk moth [60] to determine their preferred choice. However, the accuracy of the chosen AM process can have a strong influence as the result might not be detailed enough to lure real insects [61].

Products built with AM processes undergo changes overtime or during the cooling period. With the development of smart materials, $4 \mathrm{D}$ printing tries to increase this change and integrate it in the design of the object. The objective is to change the shape or the function of an object depending on time or on the environmental conditions [62]. 4D-printed biomimetic structures [63] may give access to new design opportunities in insect biomimetics in the future.

\section{Conclusion}

As this survey shows, Additive Manufacturing using insects as templates is in its early days but is burgeoning. We expect to see major breakthroughs in a not too distant future. Indeed, the major technologies are already available: printing tiny details or huge structures, printing with different materials, or ones which change over time or over space. However, the challenge lies in the integration of technologies which may be principally not impossible but conceptually hard to realize in practice (e.g. extending photo polymerization technology, e.g. Nanoscribe (Eggenstein-Leopoldshafen, Germany), to multimaterial printing). The market will drive the speed of this evolution and, once this integration is achieved, we will see a flurry of very realistic and functional insect bio-inspired parts being produced, with levels of detail true to the real structures. 


\section{Interesting articles}

${ }^{* *}[8]$ : Stereolithography process was enhanced to generate water support structures which are easily removable.

*[21] : The authors reproduced micro-structures at the surface of some insects called sprintails and that are known to be water-repellent. Thanks to Additive Manufacturing, they could modify the geometry of the structures so the surface would become repellent to any liquid.

${ }^{* *}[28]$ : With the use of Additive Manufacturing, the roles of single thread mechanical strength and spider web geometry in the overall mechanical strength of a spiderweb is better understood.

*[30] : Needles with designed inspired from honeybee sting give less pain than traditional needles.

${ }^{* *}[32]$ : Pneumatic soft actuators designs were inspired by the arrangement of fiber in muscles and were fabricated through Additive Manufacturing.

*[38] : Caterpillar locomotion is mimicked by a 3D-printed soft robot.

*[49] : Thanks to Additive Manufacturing, very realistic dragonfly-inspired wings were fabricated and the authors showed the importance of the membrane of the wing in its overall mechanical resistance.

*[55] : Micro-optics were successfully fabricated with Additive Manufacturing.

*[58] : An acoustic device inspired by locust and built with Additive Manufacturing gave insights to better design frequency-selective devices.

\section{References}

[1] F. G. Howarth, “Cave insects,” in Encyclopedia of insects (Second edition), pp. 139 - 143, 2009.

[2] K. I. Jönsson, E. Rabbow, R. O. Schill, M. Harms-Ringdahl, and P. Rettberg, "Tardigrades survive exposure to space in low Earth orbit," Current Biology, vol. 18, no. 17, pp. 729-731, 2008.

[3] J. F. Vincent and U. G. Wegst, "Design and mechanical properties of insect cuticle," Arthropod Structure and Development, vol. 33, no. 3, pp. 187-199, 2004.

[4] S. N. Gorb, "Insect-Inspired Technologies: Insectx as a Source for Biomimetics," in Insect Biotechnology (A. Vilcinskas, ed.), pp. 241-264, Springer, 2011.

[5] A. Dijkshoorn, P. Werkman, M. Welleweerd, G. Wolterink, B. Eijking, J. Delamare, R. Sanders, and G. J. Krijnen, "Embedded sensing: Integrating sensors in 3-D printed structures," Journal of Sensors and Sensor Systems, vol. 7, no. 1, pp. 169-181, 2018.

[6] A. Anastasiou, C. Tsirmpas, A. Rompas, K. Giokas, and D. Koutsouris, "3D Printing: Basic concepts Mathematics and Technologies," in IEEE 13th International Conference on Bioinformatics and Bioengineering, (http://dx.doi.org/10.1109/BIBE.2013.6701672), 2013.

[7] W. Gao, Y. Zhang, D. Ramanujan, K. Ramani, Y. Chen, C. B. Williams, C. C. Wang, Y. C. Shin, S. Zhang, and P. D. Zavattieri, "The status, challenges, and future of additive manufacturing in engineering," Computer Aided Design, vol. 69, pp. 65-89, 2015. 
[8] J. Jin and Y. Chen, "Highly removable water support for Stereolithography," Journal of Manufacturing Processes, vol. 28, pp. 541-549, 2017.

[9] D. Espalin, J. Ramirez, F. Medina, and R. Wicker, "Multi-Material, Multi-Technology FDM System," Rapid Prototyping Journal, vol. 20, no. 3, pp. 236-244, 2014.

[10] L. Mogas-Soldevila and N. Oxman, "Water-based Engineering \& Fabrication: Large-Scale Additive Manufacturing of Biomaterials," Materials Research Society Proceedings, vol. 1800, pp. 1-6, 2015.

[11] P. Sitthi-Amorn, J. E. Ramos, Y. Wang, J. Kwan, J. Lan, W. Wang, and W. Matusik, "MultiFab : a machine vision assisted platform for multi- material 3D printing," ACM Transactions on Graphics (TOG), vol. 34, no. 4, p. 129, 2015.

[12] K. Rajan, I. Roppolo, A. Chiappone, S. Bocchini, D. Perrone, and A. Chiolerio, "Silver nanoparticle ink technology: state of the art," Nanotechnology, Science and Applications, vol. 9, pp. 1-13, 2016.

[13] R. L. Truby and J. A. Lewis, "Printing soft matter in three dimensions," Nature, vol. 540, no. 7633, pp. 371-378, 2016.

[14] C. Lee and J. A. Tarbutton, "Electric poling-assisted additive manufacturing process for PVDF polymerbased piezoelectric device applications," Smart Materials and Structures, vol. 23, no. 9, 2014.

[15] ASTM, "Astm f2792 astm f2792: Standard terminology for additive manufacturing technologies."

[16] I. G. N. K. H. D. Ngo TD, Kashani A, "Additive manufacturing (3d printing): a review of materials, methods, applications and challenges. , 143. ngo td, kashani a, imbalzano g, nguyen kt, hui d: Additive manufacturing (3d printing): a review of materials, methods, applications and challenges. compos part b: Eng 2018, 143:172-196.," Composites Part B, vol. 143, pp. 172-196, 2018.

[17] M. Vaezi, S. Chianrabutra, B. Mellor, and S. Yang, "Multiple material additive manufacturing - Part 1: a review," Virtual and physical prototyping, vol. 8, no. 1, pp. 19 - 50, 2013.

[18] G. Pohl and W. Nachtigall, "Spider Webs : Tent Roofs," in Biomimetics for Architecture \& Design : NatureAnalogies-Technology, ch. 5.7.2, pp. 173 - 175, Springer, 2015.

[19] U. G. K. Wegst and M. F. Ashby, "The mechanical efficiency of natural materials," Philosophical Magazine, vol. 84, no. 21, pp. 2167-2181, 2004.

[20] U. G. Wegst, H. Bai, E. Saiz, A. P. Tomsia, and R. O. Ritchie, "Bioinspired structural materials," Nature Materials, vol. 14, no. 1, pp. 23-36, 2015.

[21] X. Liu, H. Gu, M. Wang, X. Du, B. Gao, A. Elbaz, L. Sun, J. Liao, P. Xiao, and Z. Gu, "3D Printing of Bioinspired Liquid Superrepellent Structures,” Advanced Materials, vol. 30, no. 22, 2018.

[22] B. G. Compton and J. A. Lewis, "3D-printing of lightweight cellular composites," Advanced Materials, vol. 26, no. 34, pp. 5930-5935, 2014.

[23] N. Du, X. Y. Liu, J. Narayanan, L. Li, M. Lek Min Lim, and D. Li, "Design of superior spider silk: From nanostructure to mechanical properties," Biophysical Journal, vol. 91, no. 12, pp. 4528-4535, 2006.

[24] C. Mandrycky, Z. Wang, K. Kim, and D. H. Kim, "3D bioprinting for engineering complex tissues," Biotechnology Advances, vol. 34, no. 4, pp. 422-434, 2016.

[25] E. Desimone, K. Schacht, T. Jüngst, J. Groll, and T. Scheibel, "Biofabrication of 3D constructs: fabrication technologies and spider silk proteins as bioinks," Pure and applied chemistry, vol. 87, no. 8, pp. 737 $-749,2015$.

[26] N. Oxman, M. Kayser, J. Laucks, and M. Firstenberg, "Robotically controlled fiber-based manufacturing as case study for biomimetic digital fabrication," in Green Design, Materials and Manufacturing Processes, pp. 473-478, CRC Press (London), 2013. 
[27] V. Dikshit, N. Prasanth, J. Kumar, Y. Yap, and W. Yeong, "Investigation of quasi static indentation on 3D printed honeycomb based truncated-pyramid square structure," in Proceedings of the 2nd International Conference on Progress in Additive Manufacturing, pp. 116-121, 2016.

[28] Z. Qin, B. G. Compton, J. A. Lewis, and M. J. Buehler, "Structural optimization of 3D-printed synthetic spider webs for high strength,” Nature Communications, vol. 6, no. May, pp. 1-7, 2015.

[29] S. D. Gittard, R. J. Narayan, A. Ovsianikov, and B. N. Chichkov, "Rapid Prototyping of Biomimetic Structures: Fabrication of Mosquito-like Microneedles by Two-Photon Polymerization," in Materials Research Society Proceedings V1239, pp. VV01-11, 2010.

[30] M. Sahlabadi and P. Hutapea, "Novel design of honeybee-inspired needles for percutaneous procedure," Biomimetics \& Bioinspiration, vol. 13, p. 036013, 2018.

[31] A. Zolfagharian, A. Z. Kouzani, S. Y. Khoo, A. A. A. Moghadam, I. Gibson, and A. Kaynak, "Evolution of 3D printed soft actuators," Sensors and Actuators, A: Physical, vol. 250, pp. 258-272, 2016.

[32] M. Schaffner, J. A. Faber, L. Pianegonda, P. A. Rühs, F. Coulter, and A. R. Studart, "3D printing of robotic soft actuators with programmable bioinspired architectures," Nature Communications, vol. 9, no. 1, p. 878, 2018.

[33] J. G. Cham, S. A. Bailey, J. E. Clark, R. J. Full, and M. R. Cutkosky, "Fast and Robust: Hexapedal Robots via Shape Deposition Manufacturing," The International Journal of Robotics Research, vol. 21, no. 10-11, pp. 869-882, 2002.

[34] J. Aguilar, T. Zhang, F. Qian, M. Kingsbury, B. McInroe, N. Mazouchova, C. Li, R. Maladen, C. Gong, M. Travers, R. L. Hatton, H. Choset, P. B. Umbanhowar, and D. I. Goldman, "A review on locomotion robophysics: The study of movement at the intersection of robotics, soft matter and dynamical systems," Reports on Progress in Physics, vol. 79, no. 11, p. 110001, 2016.

[35] S. Aditya, J. Ignasov, K. Filonenko, J. Larsen, E. Baird, J. Hallam, B. S., A. Kovalev, S. Gorb, L. Duggen, and P. Manoonpong, "Bio-Inspired Design and Kinematic Analysis of Dung Beetle-Like Legs," The 2nd International Symposium on Swarm Behavior and Bio-Inspired Robotics, no. October, 2017.

[36] F. Li, W. Liu, X. Fu, G. Bonsignori, U. Scarfogliero, C. Stefanini, and P. Dario, "Jumping like an insect: Design and dynamic optimization of a jumping mini robot based on bio-mimetic inspiration," Mechatronics, vol. 22, no. 2, pp. 167-176, 2012.

[37] H. T. Lin, G. G. Leisk, and B. Trimmer, “GoQBot: A caterpillar-inspired soft-bodied rolling robot,” Bioinspiration and Biomimetics, vol. 6, no. 2, 2011.

[38] T. Umedachi, V. Vikas, and B. A. Trimmer, "Softworms: The design and control of non-pneumatic, 3Dprinted, deformable robots," Bioinspiration and Biomimetics, vol. 11, no. 2, p. 0, 2016.

[39] S. A. Bailey, J. G. Cham, M. R. Cutkosky, and R. J. Full, "Biomimetic Robotic Mechanisms via Shape Deposition Manufacturing," in International Symposium on Robotics Research, (Snowbird,Utah), pp. 321327, 1999.

[40] R. R. Ma, J. T. Belter, and A. M. Dollar, "Hybrid Deposition Manufacturing: Design Strategies for Multimaterial Mechanisms Via Three-Dimensional Printing and Material Deposition," Journal of Mechanisms and Robotics, vol. 7, no. 2, p. 021002, 2015.

[41] J. F. Laliberté, K. L. Kraemer, J. W. Dawson, and D. Miyata, "Design and Manufacturing of Biologically Inspired Micro Aerial Vehicle Wings Using Rapid Prototyping," International Journal of Micro Air Vehicles, vol. 5, no. 1, pp. 15-38, 2013.

[42] C. Richter and H. Lipson, "Untethered Hovering Flapping Flight of a 3D-Printed Mechanical Insect," Artificial Life, vol. 17, no. 2, pp. 73-86, 2011. 
[43] M. Jaffar-Bandjee, T. Steinman, K. Gijs, and J. Casas, "Microphysics of the olfactory antenna of the moth Samia cynthia," In progress.

[44] B. E. Gravel, P. Y. Wong, P. T. Starks, and J. a. Pechenik, "The use of artificial shells for exploring shell preference in the marine hermit crab Pagurus longicarpus (Say)," Annales Zoologici Fennici, vol. 41, no. 3, pp. 477-485, 2004.

[45] T. A. Ward, M. Rezadad, C. J. Fearday, and R. Viyapuri, "A Review of Biomimetic Air Vehicle Research: 1984-2014," International Journal of Micro Air Vehicles, vol. 7, no. 3, pp. 375-394, 2015.

[46] H. Liu, S. Ravi, D. Kolomenskiy, and H. Tanaka, "Biomechanics and biomimetics in insect-inspired flight systems," Philosophical Transactions of the Royal Society B, vol. 371, no. 1704, p. 20150390, 2016.

[47] P. Gopalakrishnan and D. K. Tafti, "Effect of Wing Flexibility on Lift and Thrust Production in Flapping Flight,” AIAA Journal, vol. 48, no. 5, pp. 865-877, 2010.

[48] K. C. Moses, S. C. Michaels, M. Willis, and R. D. Quinn, "Artificial Manduca sexta forewings for flappingwing micro aerial vehicles: How wing structure affects performance," Bioinspiration and Biomimetics, vol. 12, no. 5, p. aa7ea3, 2017.

[49] E. Salami, P. B. Ganesan, T. A. Ward, R. Viyapuri, and F. I. Romli, "Design and mechanical analysis of a 3D-printed biodegradable biomimetic micro air vehicle wing," IOP Conference Series: Materials Science and Engineering, vol. 152, no. 1, 2016.

[50] R. Niiyama, Y. Kawahara, and Y. Kuniyoshi, "Multimaterial 3D Reconstruction of Beetle Flapping-Wing Mechanisms," in 8th International Symposium on Adaptative Motion of Animals and Machines, pp. 4849, 2017.

[51] L. J. Burton, N. Cheng, C. Vega, J. Andrés, and J. W. Bush, "Biomimicry and the culinary arts," Bioinspiration and Biomimetics, vol. 8, no. 4, 2013.

[52] G. J. Krijnen and R. G. Sanders, "Recent Developments in Bio-Inspired Sensors Fabricated by Additive Manufacturing Technologies," Advances in Science and Technology, vol. 100, pp. 197-206, 2016.

[53] T. L. Spencer, N. Lavrik, and D. L. Hu, "Synthetic moth antennae fabricated as preconcentrator for odor collection," in ISOEN 2017 - ISOCS/IEEE International Symposium on Olfaction and Electronic Nose, pp. 1-3, 2017.

[54] Y. M. Song, Y. Xie, V. Malyarchuk, J. Xiao, I. Jung, K. J. Choi, Z. Liu, H. Park, C. Lu, R. H. Kim, R. Li, K. B. Crozier, Y. Huang, and J. A. Rogers, "Digital cameras with designs inspired by the arthropod eye," Nature, vol. 497, no. 7447, pp. 95-99, 2013.

[55] S. Juodkazis, "Manufacturing: 3D printed micro-optics," Nature Photonics, vol. 10, no. 8, pp. 499-501, 2016.

[56] J. Luo, Y. Guo, and X. Wang, "Rapid fabrication of curved microlens array using the 3D printing mold," Optik, vol. 156, pp. 556-563, 2018.

[57] D. Gu, "Materials creation adds new dimensions to 3D printing," Science Bulletin, vol. 61, no. 22, pp. 1718-1722, 2016.

[58] R. Domingo-Roca, B. Tiller, J. C. Jackson, and J. F. C. Windmill, "Bio-inspired 3D-printed piezoelectric device for acoustic frequency selection,” Sensors and Actuators, A: Physical, vol. 271, pp. 1-8, 2018.

[59] B. Kwak and J. Bae, "Design of hair-like appendages and comparative analysis on their coordination toward steady and efficient swimming," Bioinspiration and Biomimetics, vol. 12, no. 3, 2017.

[60] E. O. Campos, Plant-Pollinator Interactions in an Ecological and Evolutionary Context: The Promising Role of 3D-Printing Technology and Mathematical Modeling. PhD thesis, University of Washington, 2017. 
[61] M. J. Domingue, D. P. Pulsifer, M. S. Narkhede, L. G. Engel, R. J. Martín-Palma, J. Kumar, T. C. Baker, and A. Lakhtakia, "Fine-scale features on bioreplicated decoys of the emerald ash borer provide necessary visual verisimilitude," in Bioinspiration, Biomimetics and Bioreplication 2014, vol. 9055, p. 905507, International Society for Optics and Photonics, 2014.

[62] F. Momeni, S. M. Mehdi Hassani.N, X. Liu, and J. Ni, “A review of 4D printing," Materials and Design, vol. 122, pp. 42-79, 2017.

[63] A. Sydney Gladman, E. A. Matsumoto, R. G. Nuzzo, L. Mahadevan, and J. A. Lewis, "Biomimetic 4D printing," Nature Materials, vol. 15, no. 4, pp. 413-418, 2016. 